\title{
Changes in the activity of connective tissue matrix enzymes in the metabolic syndrome
}

\author{
Jolanta Mieczkowskaํ, Jerzy Mosiewicz¹, Wojciech Barud ${ }^{1}$, Wojciech Kwaśniewski²
}

${ }^{1}$ Chair and Department of Internal Medicine, Medical University of Lublin, Poland 2Students' Scientific Association of Department of Medical University of Lublin, Poland

Submitted: 20 November 2009

Accepted: 24 March 2010

Arch Med Sci 2011; 7, 4: 634-641

DOI: 10.5114 /aoms.2011.24133

Copyright (c) 2011 Termedia \& Banach

\section{Abstract}

Introduction: Early atherosclerotic changes in the endothelium associated with metabolic syndrome are generated with the participation of inflammatory cells, cytokines and enzymes of the extracellular matrix. The study is aimed at a comparison between the activity of inflammatory agents, tumour necrosis factor $\alpha$ (TNF- $\alpha$ ) and the enzymes of the connective tissue matrix in the blood of healthy female patients as well as those suffering from the metabolic syndrome. Material and methods: The examination included 35 women with metabolic syndrome (MS). The control group (C) comprised 35 healthy women. Lipidogram, C-reactive protein level (CRP), fasting glucose level (FGL), matrix metalloproteinase (MMP)-8 and -9 activity, tissue inhibitor of metalloproteinase-1 (TIMP-1) and TNF- $\alpha$ levels in blood were determined.

Results: As compared with the control group, the level of inflammatory factors and the activity of extracellular matrix enzymes in the metabolic syndrome were statistically higher $(p<0.05)$ and concerned the following parameters: TNF- $\alpha$ $(\mathrm{pg} / \mathrm{ml})$ : MS $6.59 \pm 3.18$, C $4.78 \pm 2.91$; CRP $(\mathrm{mg} / \mathrm{dl})$ : MS $2.18 \pm 2.04, \mathrm{C} 1,26 \pm 1.35$; TIMP-1 (ng/ml): MS 265.5 \pm 2.9 , C $205.4 \pm 72.6$; MMP-9 (ng/ml): MS $198.2 \pm 138.6$, C $138.6 \pm 116.1$. Statistically significant correlations were also found between TIMP-1 and the following factors: $\mathrm{BMI}(R=0.400, p<0.001)$, waist/hip ratio (WHR) $(R=0.278, p<0.05)$, waistline $(R=0.417, p<0.001)$, FGL $(R=0.290$, $p<0.05)$, HDL cholesterol $(R=-0.253, p<0.05)$ and triglycerides $(R=0.269$, $p<0.05)$. There were positive correlations of MMP-9 with FGL $(R=0.446$, $p<0.001)$ and waistline $(R=0.260, p<0.05)$; MMP-8 with FGL $(R=0.308$, $p<0.05)$; and CRP with BMI $(R=0.370, p<0.01)$, WHR $(R=0.325, p<0.01)$ and waistline $(R=0.368, p<0.01)$.

Conclusions: Metabolic syndrome is connected with higher activity of cytokines (TNF- $\alpha$ ), inflammatory markers (CRP) and matrix enzymes (MMP-9, MMP-8, TIMP-1).

Key words: metalloproteinase, tissue inhibitors of metalloproteinases, cytokines, metabolic syndrome, atherosclerosis.

\section{Introduction}

Risk factors contributing to the metabolic syndrome (disorders of lipid and carbohydrate metabolism, obesity, arterial hypertension) may participate in the development of atherogenesis. These coronary artery disease risk factors can have an impact on the activity of connective tissue matrix.

The enzymes, in turn, are responsible for the metabolism and degradation of connective tissue. The major role in the inflammatory process of atherosclerosis is played by the endothelium, extracellular
Corresponding author: Jolanta Mieczkowska Chair and Department of Internal Medicine Medical University of Lublin SPSK Nr 1

16 Staszica

20-081 Lublin, Poland Phone/fax: +48 815327717 E-mail: jo.mie@poczta.onet.pl 
matrix, and inflammatory cells of vascular smooth muscle [1-3].

The first papers on the participation of matrix in the pathogenesis of atherosclerosis were published by Comejo et al. [4]. Metalloproteinases are factors which regulate the composition of extracellular matrix; they degrade the majority of its components and basement membranes, and they stimulate cytokines/chemokines secreted by macrophages, smooth muscle cells and active endothelial cells [5].

In the opinion of some authors, cardiovascular risk factors correlate with the activity of metalloproteinases and their inhibitors [6, 7]. Untreated familial hypercholesterolaemia changes the activity of cytokines and enzymes [8]. In hypertensive patients, raised levels of metalloproteinase (MMP)-2, MMP-9 and tissue inhibitor of metalloproteinase-1 (TIMP-1) compared with the control group were described, which determined the matrix composition and increase in collagen type I deposits at the expense of other matrix components in the cell wall [9]. Taking part in the inflammation, the MMP-TIMP complexes regulate the arterial blood pressure by influencing the cell wall tension; they participate in generating aortic aneurysm and vascular rebuilding and also in coagulation and angiogenesis processes [10]. The increased MMP-2 and -9 activity may accompany hyperglycaemia and presence of diabetic microangiopathy $[11,12]$. Lipid metabolism is also connected with the activity of metalloproteinases. In the studies on transgenic mice in which the apolipoprotein $E$ (ApoE) gene was blocked, the influence of atherogenic diet and macrophage-produced MMP-1 on the development of atherosclerosis was investigated. Less advanced atherosclerotic changes in the endothelium, lower content of collagen and more beneficial effect on extracellular matrix remodelling in the presence of MMP-1 were observed [5]. Acute cardiovascular episodes also proceed with the activation of matrix enzymes within the atheromatous plaque [13].

The study aimed to compare the activity of the inflammatory process and enzymes of connective tissue matrix in patients suffering from the metabolic syndrome without clinical manifestation of atherosclerosis with that state occurring in healthy women.

\section{Material and methods}

Thirty-five women (mean age $51.4 \pm 4.4$ years) were qualified for the examination. In addition, they suffered from the metabolic syndrome and fulfilled the following criteria: waistline $\geq 80 \mathrm{~cm}$ and additionally 2 out of 4 cardiovascular risk factors concentration of fasting glucose in the blood $>100 \mathrm{mg} / \mathrm{dl}$, arterial pressure RR $>135 / 80 \mathrm{mmHg}$ (an average was taken from two measurements, arterial blood pressure after rest was taken) or hypertension diagnosed earlier, HDL cholesterol concentration in blood $(\mathrm{HDL})<50 \mathrm{mg} / \mathrm{dl}$, triglycerides (TG) concentration $>150 \mathrm{mg} / \mathrm{dl}$ (International Diabetes Federation) (International Diabetes Federation. www.idf.org, 2005) [14].

The control group included 35 healthy women, comparable with respect to age (mean age $50.18 \pm$ 4.14 years), without abdominal obesity and not fulfilling the metabolic syndrome criteria.

These groups were separated during the population research from Lubelszczyzna in Poland from 758 patients participating in the population examination - chosen at random.

Criteria for exclusion from the study were as follows: earlier diagnosed myocardial ischaemia, earlier diagnosed cerebral stroke, heart failure, peripheral vessel disease, severe organic and systemic disease, rheumatic diseases, using hormone replacement therapy or any other form of medication. Until now changes in the matrix enzyme activity have been described in relation to the converting enzyme blockers [15].

\section{Laboratory notations}

To examine the levels of lipids and glucose, blood samples were taken on an empty stomach after $12 \mathrm{~h}$ of fasting into test tubes from the kit, specially prepared for that purpose.

The lipidogram was measured using a direct enzymatic method, bioMerieux kits and COBAS INTEGRA 600 analyser. The producer's instructions were strictly followed. The serum was stored frozen at $-25^{\circ} \mathrm{C}$.

To determine the levels of total cholesterol, the enzymatic and colorimetric method was used. The principle of the method was as follows: cholesterol esterase hydrolyses cholesterol esters to free cholesterol and fatty acids. Cholesterol oxidase then catalyses cholesterol oxidation to the form of cholest-4-en-3-one and hydrogen peroxide. In the presence of peroxidase, under the influence of hydrogen peroxide, there follows oxidative connection of phenol and 4-aminoantipyrine and the production of red colouring of quinone imine chromogen. The intensity of colouring is directly proportional to the cholesterol concentration. The determination was made by the measure of absorption increase at wavelength of $512 \mathrm{~nm}$. $120-200 \mathrm{mg} / \mathrm{dl}$ were assumed as reference values of total cholesterol in women.

In the automated method of direct serum HDL cholesterol determination, polyethylene glycol (PEG) modified enzymes and dextran sulfate were used. Enzymes modified by PEG (cholesterol esterase and oxidase) reveal a selective catalytic activity towards lipoprotein fractions. Cholesterol esters undergo quantitative decomposition into free cholesterol and fatty acids under the influence of cholesterol 
esterase. In the presence of oxygen, cholesterol is oxidised by oxidase to $\Delta 4$-cholestenone and hydrogen peroxide. The intensity of blue colouring is directly proportional to HDL concentration in the sample. Determination was made by the measurement of absorption increase at wavelength of $583 \mathrm{~nm}$. Reference values of HDL cholesterol in women were assumed as $>55 \mathrm{mg} / \mathrm{dl}$.

Triglycerides - glycerol esters with 3 long chain fatty acids were determined using an enzymatic method. To obtain full hydrolysis of triglycerides to glycerol, lipoprotein lipase from microorganisms was used and then oxidation to dihydroxyacetone and hydrogen peroxide was applied. The obtained hydrogen peroxide reacts with 4-aminophenazone and 4-chlorophenol with the participation of peroxidase creating a red coloured compound. The intensity of red colouring is proportional to triglycerides concentration and can be measured photometrically. The reference values of triglycerides in women were assumed as $<200 \mathrm{mg} / \mathrm{dl}$.

The level of LDL cholesterol was measured according to Friedewald's formula (LDL cholesterol $(\mathrm{mg} / \mathrm{dl})$ $=$ total cholesterol $(\mathrm{mg} / \mathrm{dl})-\mathrm{HDL}$ cholesterol $(\mathrm{mg} / \mathrm{dl})$ - triglycerides $(\mathrm{mg} / \mathrm{dl}) / 5)$, taking into account the limitations connected with a high (above $450 \mathrm{mg}$ ) level of triglycerides (in one patient from the studied group). The reference values of LDL cholesterol in women were established as $<135 \mathrm{mg} / \mathrm{dl}$.

The concentration of fasting glucose was determined using the enzymatic method with glucose oxidase and COBAS INTEGRA 600 analyser. Reference values of fasting glucose were established as 60-100 mg/dl.

Body mass index (BMI) and waist-hip ratio (WHR) were calculated. The C-reactive protein (CRP) in blood was examined employing the turbidimetric quantitative method and using Konelab 301. The principle of the method is the immunoturbidimetric test enhanced with PEG particles. Human CRP agglutinates with those particles coated by monoclonal antibodies against human CRP. The obtained precipitate is turbidimetrically measured in a Konelab 301 analyser, using the calibration curve. The producer's instructions were strictly followed. The reference value for CRP is $0-5 \mathrm{mg} / \mathrm{l}$.

The levels of MMP-8, MMP-9, TIMP-1 and tumour necrosis factor (TNF)- $\alpha$ were determined by using the immunological test and the ELISA method.

Blood for examination was taken on an empty stomach between 10.00 am and 1 pm into specially prepared test tubes with EDTA as the anticoagulant and centrifuged for $15 \mathrm{~min}$ at room temperature. The plasma obtained during centrifugation was then divided into samples and stored in a freezer at $\leq-25^{\circ} \mathrm{C}$.

The levels of MMP-9, MMP-8 and TIMP-1 were determined using the kits of R\&D Systems
(Minneapolis, MN 55413, USA): Quantikine Human MMP-9 (total) Immunoassay (catalogue number DTM 900), MMP-8 (total) Immunoassay (catalogue number DTM 800), Human TIMP-1 Immunoassay (catalogue number DTM 100), Human TNF- $\alpha$ / TNFSF1A Immunoassay (catalogue number DTA00C). The producer's instructions were strictly followed. The immunoenzymatic tests were based on the ELISA method. They are designed for quantitative determination of MMP-9, MMP-8, TIMP-1, TNF- $\alpha$ on biological material. In each case the calibration curve was made. The results were read using the III universal Bio-Tek ELX 800 microplate reader.

The levels of MMP-9, MMP-8, and TIMP-1 were expressed in $\mathrm{ng} / \mathrm{ml}$, and TNF- $\alpha$ in $\mathrm{pg} / \mathrm{ml}$. The D-dimer level in blood was determined using the immunofluorescent method and BIO-MERIEUX kit. Roche reagents were used for examinations and the results were read with a COBAS INTEGRA 400 analyser. The reference value for D-dimers was $<500 \mathrm{FEU} / \mathrm{ml}$.

The fibrinogen level was determined using the coagulation method and SYSMEX CA-560. Reference values for fibrinogen were assumed as 200-400 mg/dl.

\section{Statement of ethics}

All the examinations were performed with the written consent of the patients. Approval to perform the study was obtained from the Bioethical Commission of the Medical University of Lublin (KE-0254/184; 185/2006).

\section{Statistic analysis}

Results were subjected to statistical analysis using the Statistica 5.0 computer program. Nonparametric Mann-Whitney $U$ tests were used for the statistical workout during the comparison of the groups. Relationships between various parameters were studied using Spearman's test and determining the $R$ correlation coefficient. The value of $p<0.05$ was assumed as statistically significant.

\section{Results}

In the studied group there were 13 menstruating women; the remaining 22 women were in the postmenopausal period. In the control group there were 12 menstruating women and the others were in the postmenopausal period.

Table I shows the comparison of mean values of BMI, WHR, waistline, lipid levels, fasting glucose and arterial blood pressure in the studied women with metabolic syndrome and those from the control group. All the studied parameters were significantly more unfavourable in the group of women with metabolic syndrome compared with the control group. 
Table I. Comparison of mean values of BMI, WHR, waistline, lipid levels, fasting glucose and arterial blood pressure in the studied women with metabolic syndrome and those from the control group

\begin{tabular}{|lccc|}
\hline Parameters & $\begin{array}{c}\text { MS, average } \pm \text { SD } \\
\text { (Minimum-maximum) }\end{array}$ & $\begin{array}{c}\text { C, average } \pm \text { SD } \\
\text { (Minimum-maximum) }\end{array}$ & Value of $p$ \\
\hline BMl $\left[\mathrm{kg} / \mathrm{m}^{2}\right]$ & $30.87 \pm 5.18(24.8-51.0)$ & $23.50 \pm 2.67(17.97-30.60)$ & $<0.0001$ \\
\hline WHR & $0.8696 \pm 0.0586(0.70-0.97)$ & $0.7874 \pm 0.0518(0.63-0.84)$ & $<0.0001$ \\
\hline Waistline $[\mathrm{cm}]$ & $100.31 \pm 13.53(85.0-135.0)$ & $77.51 \pm 8.34(60.0-92.0)$ & $<0.0001$ \\
\hline TCh $[\mathrm{mg} / \mathrm{dl}]$ & $245.21 \pm 65.99(165.0-493.0)$ & $224.86 \pm 37.50(145-239)$ & 0.3130 \\
\hline LDL $[\mathrm{mg} / \mathrm{dl}]$ & $156.08 \pm 67.58(76.0-404.0)$ & $138.28 \pm 29.90(91-239)$ & 0.3650 \\
\hline HDL $[\mathrm{mg} / \mathrm{dl}]$ & $56.82 \pm 13.17(34.0-86.0)$ & $69.11 \pm 15.27(44-103)$ & $0.0017^{\star *}$ \\
\hline TG $[\mathrm{mg} / \mathrm{dl}]$ & $154.38 \pm 94.31(42.0-455.0)$ & $96.57 \pm 46.01(42-225)$ & $0.0024^{* *}$ \\
\hline FGL $[\mathrm{mg} / \mathrm{dl}]$ & $95.77 \pm 15.20(69.0-132.0)$ & $86.29 \pm 11.26(68.0-123.0)$ & $0.0060^{* *}$ \\
\hline RRs $[\mathrm{mmHg}]$ & $149.43 \pm 19.20(120-200)$ & $134.71 \pm 21.32(100-180)$ & $0.0013^{* *}$ \\
\hline RRd $[\mathrm{mmHg}]$ & $93.43 \pm 11.68(70-110)$ & $85.1429 \pm 14.38(60-110)$ & $0.0100^{\star *}$ \\
\hline RRs-d $[\mathrm{mmHg}]$ & $49.57 \pm 15.97(30-100)$ & $49.57 \pm 11.14(30-80)$ & $0.0337^{*}$ \\
\hline
\end{tabular}

$p$ - level of statistical significance $\left({ }^{*} p<0.05,{ }^{* *} p<0.01,{ }^{* * *} p<0.001\right), S D-$ standard deviation, MS - patients with the metabolic syndrome, $C$ - control group, BMl - body mass index $\left(\mathrm{kg} / \mathrm{m}^{2}\right)$, WHR - waist/hip ratio, ChL - total cholesterol levels, $L D L-L D L$ cholesterol levels, HDL - HDL cholesterol levels, TG - triglycerides, FGL - fasting plasma glucose level, RRs - systolic blood pressure, RRd - diastolic blood pressure, $R R s-d$ - the difference between systolic and diastolic pressure (pulse pressure)

Table II shows the comparison of mean blood levels of MMP- 8 and -9 , TIMP-1, TNF- $\alpha$, and CRP in the studied women with metabolic syndrome and in those from the control group. The activities of MMP-9 and tissue inhibitor of MMP-1 were significantly higher in the group of women with metabolic syndrome than in the control group. Also CRP and TNF- $\alpha$ in the blood serum of women with metabolic syndrome were significantly higher than those in the control group.
Table III shows Spearman's correlation coefficient $(R)$ for TNF- $\alpha$, MMP-9, MMP-8 and the following factors: obesity indices (BMI, WHR, waistline), fasting plasma glucose level, lipidogram (TG, HDL cholesterol levels) and pulse pressure.

Figure 1 shows Spearman's correlation coefficient (R) for TIMP-1 and the following factors: obesity indices (BMI, WHR, waistline), fasting plasma glucose level, TG and HDL cholesterol levels.

Table II. Comparison of mean blood levels of MMP-8, -9, TIMP-1, TNF- $\alpha$, CRP in the studied women with metabolic syndrome and in those from the control group

\begin{tabular}{|lccc|}
\hline Parameters & $\begin{array}{c}\text { MS, average } \pm \text { SD } \\
\text { (Minimum-maximum) }\end{array}$ & $\begin{array}{c}\text { C, average } \pm \text { SD } \\
\text { (Minimum-maximum) }\end{array}$ & Value of $p$ \\
\hline MMP-9 $[\mathrm{ng} / \mathrm{ml}]$ & $197.77 \pm 140.65(34.10-658.30)$ & $138.59 \pm 116.09(24.50-501.20)$ & $0.0196^{*}$ \\
\hline TNF- $\alpha[\mathrm{pg} / \mathrm{ml}]$ & $6.59 \pm 3.18(1.503-12.99)$ & $4.78 \pm 2.91(0.5-12.99)$ & $0.0230^{*}$ \\
\hline TIMP-1 $[\mathrm{ng} / \mathrm{ml}]$ & $265.46 \pm 77.35(142.50-432.20)$ & $205.42 \pm 72.64(74.30-422.60)$ & $0.0014^{* *}$ \\
\hline MMP-8 $[\mathrm{ng} / \mathrm{ml}]$ & $12.89 \pm 7.65(2.98-30.16)$ & $12.6417 \pm 5.84(4.38-23.64)$ & 0.9860 \\
\hline CRP $[\mathrm{mg} / \mathrm{l}]$ & $2.15 \pm 2.01(0.10-8.30)$ & $1.29 \pm 1.30(0.2-6.6)$ & $0.0393^{*}$ \\
\hline
\end{tabular}

MMP-8, MMP -9 - metalloproteinases 8 and 9, TNF- $\alpha$ - human tumor necrosis factor- $\alpha$, TIMP-1 - tissue inhibitor of metalloproteinase, CRP - C-reactive protein, other abbreviations - see Tables I

Table III. Spearman's correlation coefficients between the serum levels in blood TNF- $\alpha$, CRP, MMP-9, MMP-8 and the following factors: obesity indices (BMI, WHR, waistline), fasting plasma glucose level, lipidogram (TG, HDL cholesterol levels) and pulse pressure

\begin{tabular}{|lccccccc|}
\hline Parameters & BMI & WHR & Waistline & FGL & HDL & TG & RRs-d \\
\hline TNF- $\alpha[\mathrm{pg} / \mathrm{ml}]$ & 0.120 & 0.143 & 0.149 & 0.116 & -0.203 & 0.075 & -0.056 \\
\hline MMP-9 $[\mathrm{ng} / \mathrm{ml}]$ & 0.222 & 0.192 & $0.260^{*}$ & $0.446^{* * *}$ & -0.134 & 0.166 & 0.031 \\
\hline MMP-8 $[\mathrm{ng} / \mathrm{ml}]$ & 0.126 & -0.003 & 0.050 & $0.308^{*}$ & 0.152 & 0.119 & -0.141 \\
\hline CRP $[\mathrm{mg} / \mathrm{l}]$ & $0.370^{* *}$ & $0.325^{* *}$ & $0.368^{* *}$ & 0.155 & -0.065 & -0.096 & 0.130 \\
\hline
\end{tabular}



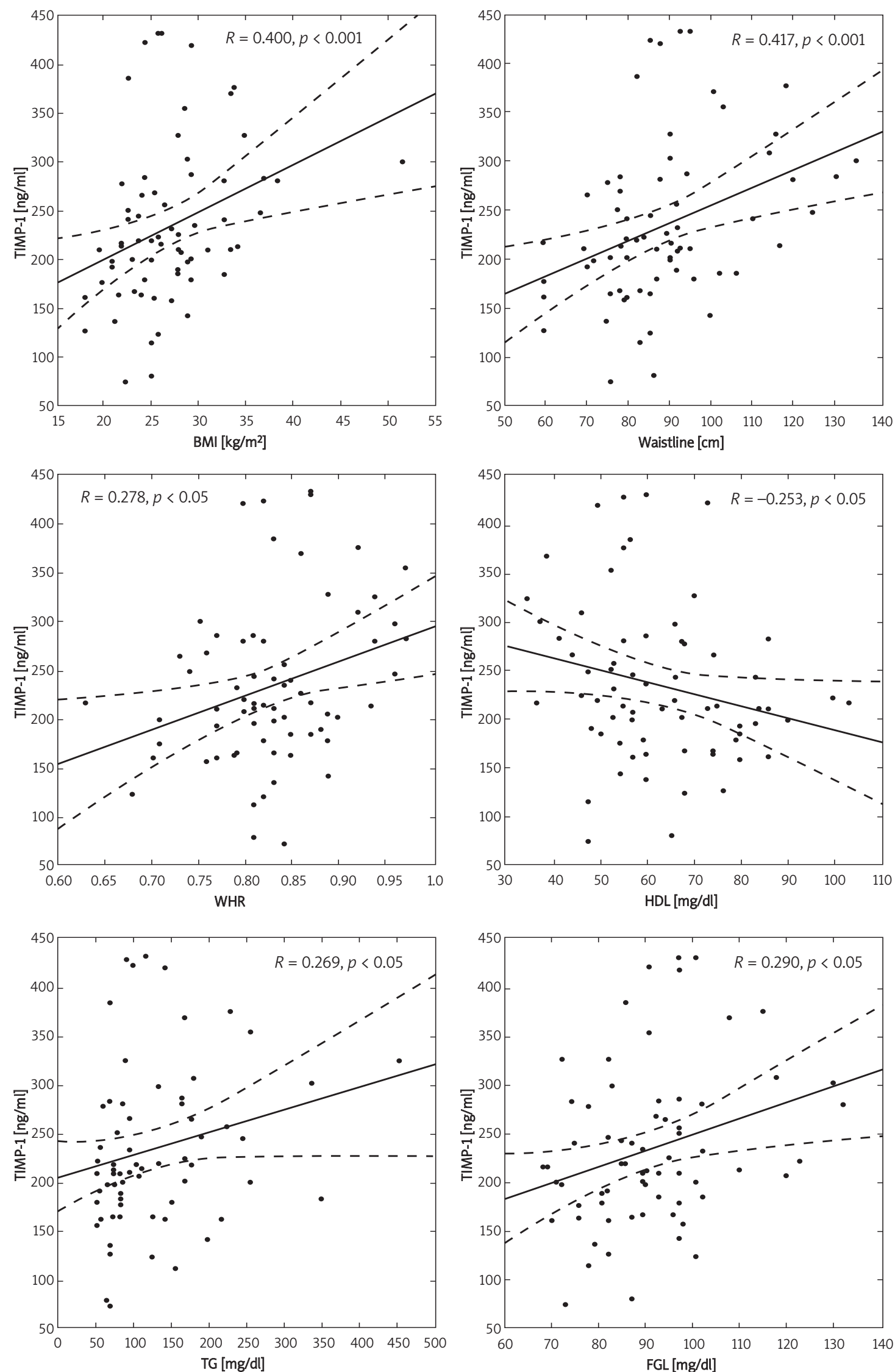

Figure 1. Spearman's correlation coefficient (R) for TIMP-1 and the following factors: obesity indices (BMI, WHR, waistline), fasting plasma glucose level, triglycerides (TG) and HDL cholesterol levels Abbreviations - see Tables / and II 
Table IV. Comparison of mean D-dimer values and fibrinogen levels between patients with metabolic syndrome and healthy women

\begin{tabular}{|lccc|}
\hline Examined groups & Parameters & Average \pm SD (minimum-maximum) & Value of $p$ \\
\hline MS & D-dimers $[\mathrm{FEU} / \mathrm{ml}]$ & $550.23 \pm 374.03(170.4-1362.7)$ & $* *$ \\
\cline { 1 - 3 } C & D-dimers $[\mathrm{FEU} / \mathrm{ml}]$ & $295.39 \pm 276.70(108.6-1162.0)$ & \\
\hline MS & Fibrinogen $[\mathrm{mg} / \mathrm{dl}]$ & $431.25 \pm 88.58(290.0-540.0)$ & $*$ \\
\hline C & Fibrinogen $[\mathrm{mg} / \mathrm{dl}]$ & $321.68 \pm 127.70(53.0-500.0)$ & \\
\hline
\end{tabular}

Abbreviations - see Tables I and II

Obesity indices significantly positively correlated with the levels of CRP and TIMP-1 in blood. Fasting glucose level significantly influenced the activities of MMP-8 and -9 and TIMP-1. The TIMP-1 was also under the significant influence of increased level of triglycerides and reduced level of $\mathrm{HDL}$. The associations between TNF- $\alpha$, TIMP-1, MMP-8, MMP-9, CRP with systolic, diastolic pressure and pulse pressure were statistically insignificant.

Table IV shows comparison of mean D-dimer values and fibrinogen levels in blood between patients with metabolic syndrome and healthy women. Both of them were significantly higher among women with metabolic syndrome.

\section{Discussion}

In the pathogenesis of atherosclerosis, a significant role is played by the inflammatory process of the vascular wall. In this case, inflammatory markers such as CRP, adhesion molecules, metalloproteinases and cytokines act as atherosclerosis predictors [16]. In our study, the level of inflammatory markers CRP and TNF- $\alpha$, agents of the coagulation system activation and fibrinolysis (D-dimers, fibrinogen) participating in the inflammatory process of atherosclerosis were higher in patients with the metabolic syndrome as compared with healthy women. Cytokines themselves, including TNF- $\alpha$, can both initiate and worsen the inflammatory condition. The inflammatory process is also worsened by the existence of other factors that trigger disorders in the endothelial and vascular wall metabolism such as hyperlipidaemia, carbohydrate disorders, and arterial hypertension $[17,18]$. The multiple functions of proinflammatory cytokines include activating the matrix synthesis, increasing endothelial permeability, allowing lipid storage in vascular wall and initiating proliferation of endothelial cells. The TNF- $\alpha$ and interleukin IL-1 induce metalloproteinase synthesis as well as curb the synthesis of tissue inhibitors of metalloproteinase. In the inflammatory process of atherosclerosis, mutual associations between inflammatory cells, cytokines, chemokines and lipids are of some importance [19-22].

The majority of connective tissue cells produce both metalloproteinases and their inhibitors.
Curbing metalloproteinase activity is caused by creating complex systems from active types of metalloproteinases and their tissue inhibitors. The TIMP-1 inactivates most MMPs [2].

In our study, the levels of both MMP-9 and the TIMP-1 were higher among patients with the metabolic syndrome as compared with the control group. Our findings were consistent with those of other authors [23, 24]. Simultaneously, the activity of these enzymes increased with greater intensity of cardiovascular risk factors contributing to the metabolic syndrome, including obesity, atherogenic lipid profile and the concentration of fasting plasma glucose in blood. The MMP-9, which downgrades mainly collagen type IV [1], is more active among patients with the metabolic syndrome. In our study, this activity was associated with fasting plasma glucose level (the highest correlation coefficient was noted between MMP levels and fasting plasma glucose level, whereas lower correlation coefficients were noted between MMP-9 level and obesity indices). Numerous publications have pointed to a greater activity of metalloproteinase MMP-9 as well as MMP-2 in type-2 diabetes [11]. This greater activity is believed to be connected with hyperglycaemia and diabetic microangiopathy [12]. Effective treatment of type 2 diabetes by using rosiglitazone reduces MMP-9 activity among patients with simultaneously diagnosed myocardial ischaemia [25]. Such data suggest that MMPs can be regarded as a marker of atherosclerosis activity [24]. In our studies, high correlation indices were found of fasting glucose levels not only with MMP-9 but also with MMP-8 and TIMP-1 levels in blood.

The development of vascular changes in diabetes can be connected not only with increased metalloproteinase activity but also with a disturbed MMP/TIMP ratio [26, 27]. Our study showed increased activity of the tissue inhibitor of MMP-1 among patients suffering from the metabolic syndrome as compared with the control group. This activity changed with the intensity of cardiovascular risk factors and was higher with increased values of the following factors: obesity, abdominal obesity, atherogenic lipid profile, and fasting plasma glucose level. Similar results were noted by other researchers [10, 28]. In the examined group, 
a positive correlation between TIMP-1 activity and numerous cardiovascular risk factors can be attributed to the protective role of TIMP-1 in relation to factors degrading extracellular matrix (MMPs) accompanied by hypertension, obesity and lipid disorders.

Similar to our study, epidemiological research conducted by Głowińska-Olszewska [29], concerning children and teenagers, shows higher MMP-9 and TIMP-1 levels in the case of overweight, obesity and arterial hypertension coexistence. Increased activity of MMP-9, TIMP-1 and MMP-2 among patients with arterial hypertension has also been observed by other authors [30, 31]. The effective treatment of arterial hypertension has, in turn, caused lower activity of MMP-9 and increased activity of tissue inhibitor of metalloproteinase TIMP-1 $[9,15]$.

Among the examined patients, an increase in obesity indices (waistline) was accompanied by an increased activity of MMP-9. Nevertheless, correlation coefficients between MMS- 8 and obesity indices were lower. According to the data found in the literature, metalloproteinase- 8 is an enzyme degrading collagen type 1 which forms atheromatous plaque. The MMP-8 can participate in the development of severe coronary condition caused by a fracture of the atheromatous plaque [32-34]. Moreover, together with MMP-9, MMP-8 can contribute to the development of a fractured aneurysm of large arterial vessels [35].

The associations between metalloproteinase activity and cardiovascular risk factors suggest that the activity of connective tissue matrix enzymes increases when an inflammatory atherosclerotic process is in progress in the vascular wall. So far, the research conducted on this subject makes it reasonable to conclude that some medicines affecting cardiovascular risk factors (rosiglitazone, inhibitors of the converting enzyme) decrease the activity of matrix enzymes [15, 25].

Metabolic syndrome concerns women at every age although it more frequently occurs after menopause. Our studied group of pre- and postmenopausal women is not numerically big; however, it was randomly selected from among 758 participants of population studies of the Lubelszczyzna region.

The future will tell whether the atherosclerotic process can be monitored by marking the activity of matrix enzymes; the issue requires further studies of larger populations.

In conclusion, the activity of factors participating in the inflammatory atherosclerotic process of the vascular wall is higher in patients with the metabolic syndrome as compared with healthy women. These factors include cytokines (TNF- $\alpha$ ), the coagulation system and fibrinolysis (D-dimers, fibrinogen), enzymes of connective tissue matrix (MMP-9, TIMP-1) and markers of inflammation (CRP).

The higher the intensity of cardiovascular risk factors, the greater the activity of matrix enzymes in blood serum. The MMP-9 activity increases with the fasting plasma glucose level. The TIMP-1 activity increases with higher obesity indices, atherogenic lipid profile and fasting glucose level. The MMP-8 activity increases with fasting glucose level.

\section{Acknowledgments}

This work was supported by a grant of the University of Lublin (159/07). We hereby thank the university for the grant.

\section{References}

1. Watanabe N, Ikeda U. Matrix metalloproteinases and atherosclerosis. Curr Atheroscler Rep 2004; 6: 112-20.

2. Dollery CM, McEwan JR, Henney AM. Matrix metalloproteinases and cardiovascular disease. Circ Res 1995; 77: 863-8.

3. Shanker J, Kakkar VV. Role of periodontal infection in cardiovascular disease: a current perspective. Arch Med Sci 2009; 5: 125-34.

4. Camejo G, Hurt-Camejo E, Olsson U, Bondjers G. Lipid mediators that modulate the extracellular matrix structure and function in vascular cells. Curr Atheroscler Rep 1999; 1: 142-9.

5. Lemaitre V, O'Byrne TK, Borczuk AC, Okada Y, Tall AR, D'Armiento J. ApoE knockout mice expressing human matrix metalloproteinase-1 in macrophages have less advanced atherosclerosis. J Clin Invest 2001; 107: 1227-34.

6. Kaddah S, Rashed L, Obaia E, Sabry D. A preliminary study: matrix metalloproteinase expression as an indicator of the hazards of shisha (nargila) smoking. Arch Med Sci 2009; 5: 570-6.

7. Barylski M, Banach M, Mikhailidis DP, Pawlicki L, Kowalski J. Decreased kidney function as a risk factor for cardiovascular events in subjects with metabolic syndrome - a pilot study. Arch Med Sci 2008; 4: 417-23.

8. El Messal M, Beaudeux JL, Drissi A, et al. Elevated serum levels of proinflammatory cytokines and biomarkers of matrix remodeling in never-treated patients with familial hypercholesterolemia. Clin Chim Acta 2006; 366: 185-9.

9. Tayebjee MH, Nadar S, Blann AD, Beevers GD, MacFadyen RJ, Lip GY. Matrix metalloproteinase-9 and tissue inhibitor of metalloproteinase-1 in hypertension and their relationship to cardiovascular risk and treatment: a substudy of the Anglo-Scandinavian Cardiac Outcomes Trial (ASCOT). Am J Hypertens 2004; 17: 764-9.

10. Ikonomidis JS, Jones JA, Barbour JR, et al. Expression of matrix metalloproteinases and endogenous inhibitors within ascending aortic aneurysms of patients with bicuspid or tricuspid aortic valves. J Thorac Cardiovasc Surg 2007; 133: 1028-36.

11. Lee SW, Song KE, Shin DS, et al. Alterations in peripheral blood levels of TIMP-1, MMP-2, and MMP-9 in patients with type-2 diabetes. Diabetes Res Clin Pract 2005; 69: 175-9.

12. Jacqueminet $S$, Ben Abdesselam O, Chapman MJ, et al. Elevated circulating levels of matrix maealloproteinase-9 
in type 1 diabetic patients with and without retinopathy. Clin Chim Acta 2006; 367: 103-7.

13. Kangavari S. Smoking increases inflammation and metalloproteinase expression in human carotid atherosclerotic plaques. Cardiovasc Pharmacol Ther 2004; 9: 291-8.

14. International Diabetes Federation. The IDF consensus worldwide definition of the metabolic syndrome: http://www.idf.org, 2005.

15. Yamamoto D, Takai S, Jin D, Inagaki S, Tanaka K, Miyazaki M. Molecular mechanism of imidapril for cardiovascular protection via inhibition of MMP-9. J Mol Cell Cardiol 2007; 43: 670-6.

16. Venugopal SK, Devaraj S, Jialal I. Effect of C-reactive protein on vascular cells: evidence for a proinflammatory, proatherogenic role. Curr Opin Nephrol Hypertens 2005; 14: 33-7.

17. Bonetti PO, Lerman LO, Lerman A. Endothelial dysfunction: a marker of atherosclerotic risk. Arterioscler Thromb Vasc Biol 2003; 23: 168-75.

18. Pasqui AL, Di Renzo M, Bova G, et al. Pro-inflammatory/anti-inflammatory cytokine imbalance in acute coronary syndromes. Clin Exp Med 2006; 6: 38-44.

19. Tziakas DN, Chalikias GK, Hatzinikolaou HI, et al. Antiinflammatory cytokine profile in acute coronary syndromes; behavior of IL-10 in association with serum metalloproteinases and inflammatory cytokines. Int J Cardiol 2003; 92: 169-75.

20. Arai KI, Lee F, Miyajima A, Miyatake S, Arai N, Yokota T. Cytokines: coordinators of inflammatory response. Ann Rev Inc 1990; 59: 783-836.

21. Mizia-Stec K, Gasior Z, Zahorska-Markiewicz B, et al. Serum tumor necrosis factor-alfa, IL-2 and IL-10 activation in stable angina and acute coronary syndromes. Coron Artery Dis 2003; 14: 431-8.

22. Sabatine MS, Morrow DA, de Lemos JA, et al. Multimarker approach to risk stratification in non-ST elevation acute coronary syndromes simultaneous assessment of troponin I, C-reactive protein, and B-type natriuretic peptide. Circulation 2002; 105: 1760-3

23. Roberts CK, Won D, Pruthi S, et al. Effect of a short-term diet and exercise intervention on oxidative stress, inflammation, MMP-9, and monocyte chemotactic activity in men with metabolic syndrome factors. J Appl Physio 2006; 100: 1657-65.

24. Goncalves FM, Jacob-Ferreira AL, Gomes VA, et al. Increased circulating levels of matrix metalloproteinase (MMP)-8, MMP-9, and pro-inflammatory markers in patients with metabolic syndrome. Clin Chim Acta 2009; 403: 173-7.

25. Marx N, Froehlich J, Siam L, et al. Antidiabetic PPAR \{gamma\}-activator rosiglitazone reduces MMP-9 serum levels in type 2 diabetic patients with coronary artery disease. Arterioscler Thromb Vasc Biol 2003; 23: 283-8.

26. Pawlak K, Pawlak D, Mysliwiec M. Circulating betachemokines and matrix metalloproteinase-9/tissue inhibitor of metalloproteinase-1 system in hemodialyzed patients-role of oxidative stress. Cytokine 2005; 31: 18-24.

27. Signorelli SS, Malaponte G, Libra M, Di Pino L, Celotta G, Bevelacqua V. Plasma levels and zymographic activities of matrix metalloproteinases 2 and 9 in type II diabetics with peripherial arterial disease. Vasc Med 2005; 10: 1-6.

28. Nanni S, Melandri G, Hanemaaijer R, et al. Matrix metalloproteinases in premature coronary atherosclerosis: influence of inhibitors, inflammation, and genetic polymorphisms. Transl Res 2007; 149: 137-44.
29. Głowińska-Olszewska B, Urban M. Elevated matrix metalloproteinase-9 and tissue inhibitor of metalloproteinase- 1 in obese children and adolescents. Metabolism 2007; 56: 799-805.

30. Tayebjee MH, Nadar SK, MacFadyen RJ, Lip GY. Tissue inhibitor of metalloproteinase-1 and matrix metalloproteinase-9 levels in patients with hypertension. Relationship to tissue Doppler indices of diastolic relaxation. Am J Hypertens 2004; 17: 770-4.

31. Derosa G, D'Angelo A, Let C, et al. Matrix metalloproteinase-2, -9, and tissue inhibitor of metalloproteinase-1 in patients with hypertension. Endothelium 2006; 13: 227-31.

32. Kato R, Momiyama Y, Ohmori R, Taniguchi H, Nakamura H, Ohsuzu F. Plasma matrix metalloproteinase-8 concentrations are associated with the presence and severity of coronary artery disease. Circ J 2005; 69: 1035-40.

33. Owen CA, Hu Z, Lopez-Otin C, Shapiro SD. Membranebound matrix metalloproteinase- 8 on activated polymorphonuclear cells is a potent, tissue inhibitor of metalloproteinase-resistant collagenase and serpinase. J Immunol 2004; 172: 7791-803.

34. Momiyama Y, Ohmori R, Tanaka N, et al. High plasma levels of matrix metalloproteinase- 8 in patients with unstable angina. Atherosclerosis 2010; 209: 206-10.

35. Wilson WR, Anderton M, Schwalbe EC, et al. Matrix metalloproteinase- 8 and -9 are increased at the site of abdominal aortic aneurysm rupture. Circulation 2006; 113: 438-45. 